\title{
Cardiogenic shock following nasal septoplasty: a case report and review of the literature
}

\author{
[Choc cardiogénique à la suite d'une septoplastie nasale : une étude de cas et une
}

revue de la littérature]

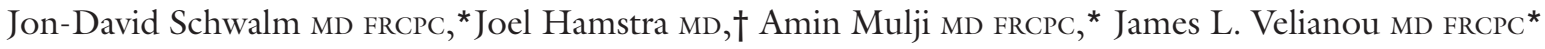

Purpose: Nasal septoplasty is a surgical procedure offered to patients with chronic snoring secondary to nasal obstruction. We describe a case of cardiogenic shock following the administration of metoprolol to treat hypertension, (likely) induced by systemic absorption of topical epinephrine used during a routine nasal septoplasty.

Clinical features: A 29-yr-old male, with no significant medical history, was scheduled for nasal septoplasty for mild nasal obstruction. Following routine anesthetic induction, cotton balls, soaked with epinephrine $(1: 1000)$, were applied to the nasal mucosa. The patient became hypertensive with a blood pressure of $207 / / 23 \mathrm{mmHg}$. Intravenous metoprolol was administered. Severe pulmonary edema ensued, with resulting hypoxic respiratory failure and cardiogenic shock. The patient was transferred to a tertiary care facility for percutaneous cardiopulmonary bypass. After five days of cardiopulmonary bypass support and six weeks of intensive care monitoring, the patient's cardiac status returned to normal limits.

Conclusion: A hypertensive response, following systemically absorbed topical vasoconstrictors, including both phenylephrine and epinephrine, can be associated with dire consequences when treated with a beta-adrenergic blocking drug and, possibly, calcium channel blockers. To prevent severe complications including; pulmonary edema, cardiogenic shock, cardiac arrest, and, possibly, death, these drug interactions need to be appreciated.

CAN J ANESTH $2008 / 55: 6 / 376-379$
Objectif : La septoplastie nasale est une procédure chirurgicale offerte aux patients souffrant de ronflements chroniques liés à une obstruction nasale. Nous décrivons ici un cas de choc cardiogénique survenu à la suite de l'administration de métoprolol pour traiter une hypertension, (probablement) provoquée par l'absorption systémique d'épinéphrine topique, un médicament utilisé lors d'une septoplastie nasale simple.

Éléments cliniques: Une septoplastie nasale a été planifiée pour un homme de 29 ans ne présentant pas d'antécédents médicaux significatifs, afin de traiter une obstruction nasale légère. À la suite d'une induction de l'anesthésie habituelle, des tampons de coton hydrophile imbibés d'épinéphrine (1:1000) ont été appliqués sur les muqueuses nasales. Le patient est devenu hypertendu avec une pression artérielle de 207//23 mmHg. Du métoprolol a été administré en intraveineuse. Un œdème pulmonaire sévère est survenu, accompagné d'une insuffisance respiratoire hypoxique et d'un choc cardiogénique. Le patient a été transféré à une unité de soins tertiaires pour obtenir une circulation extracorporelle percutanée. Après cinq jours de soutien par circulation extracorporelle et six semaines de surveillance aux soins intensifs, son état cardiovasculaire est revenu dans les limites normales.

Conclusion : Une réaction hypertensive à la suite de l'absorption systémique de vasoconstricteurs topiques (y compris la phényléphrine et l'épinéphrine) peut être associée à de graves conséquences lorsqu'elle est traitée avec un bêta-bloquant et, possiblement, avec des inhibiteurs calciques. Pour éviter les complications graves, notamment : œdème pulmonaire, choc cardiogénique, arrêt cardiaque et, possiblement, décès, ces interactions médicamenteuses doivent être prises en considération.

From the Department of Medicine, Division of Cardiology, ${ }^{*}$ Hamilton General Hospital Site; and the Department of Anesthesiology, $\dagger$ McMaster University, Hamilton, Ontario, Canada.

Address correspondence to: Dr. Jon-David Schwalm, Hamilton Health Sciences - McMaster University, 237 Barton Street East, Hamilton, Ontario L8L 2X2, Canada. Phone: 905-317-0135; Fax: 905-527-1914; E-mail: schwalj@mcmaster.ca

Disclosures: None declared.

Accepted for publication February 11, 2008.

Revision accepted March 13, 2008. 
$\mathrm{P}$ ERIOPERATIVE mortality, secondary to pulmonary edema and cardiac arrest, has been reported in two series concerning previously healthy patients undergoing otorhinolaryngological (ENT) surgery. ${ }^{1,2}$ These cases involved inciting, perioperative, hypertensive crises, thought secondary to topically-applied phenylephrine or submucosally injected epinephrine, followed by the administration of a beta-blocker for blood pressure (BP) control. ${ }^{1,2} \mathrm{We}$ present a case of cardiogenic shock following the administration of metoprolol to treat hypertension, (likely) induced by systemic absorption of topical epinephrine used during a routine nasal septoplasty. Written consent for publication was provided by the patient described herein.

\section{Clinical features}

A 29-yr-old male was referred to an ENT surgeon for assessment of symptoms involving mild nasal obstruction and disproportionate growth of his left nostril. His medical history was significant for a remote tonsillectomy, with no reported adverse reactions during anesthesia, and a gastroscopy with $H$. Pylori positive biopsy. He had no known drug allergies, and he was not taking any medications. He had no history of significant alcohol consumption or illicit drug use. He denied any cardiovascular limitations on review, and his physical examination was normal.

The patient underwent elective septoplasty under general anesthesia with oral endotracheal intubation. After securing a peripheral intravenous line and applying routine monitors, anesthesia was induced with propofol $200 \mathrm{mg}$ iv and fentanyl $50 \mathrm{\mu g}$ iv, to facilitate tracheal intubation with a $\# 8 \mathrm{~mm}$ endotracheal tube. Sevoflurane, $2.6 \%$ end-tidal concentration in oxygen, was used for maintenance of anesthesia. Following induction, cotton balls, soaked with epinephrine (1:1000), were applied to the patient's nasal mucosa. Then, $4 \mathrm{~mL}$ of lidocaine $1 \%$ with 1:200,000 epinephrine was injected locally. Within $15 \mathrm{~min}$, the patient became hypertensive with a systolic BP of 170 $\mathrm{mmHg}$. This degree of hypertension persisted and was observed, without intervention, for the remainder of the procedure. Following the $30 \mathrm{~min}$ procedure, the patient was transferred to the postanesthesia care unit (PACU) with his endotracheal tube remaining in situ. Minutes later, the patient's BP increased to $207 / 123 \mathrm{mmHg}$, with a concurrent, wide-complex, regular tachycardia at a rate of 160 beats. $\mathrm{min}^{-1}$ (Figure 1). Metoprolol $5 \mathrm{mg}$ iv, followed by another $3 \mathrm{mg}$, was administered by the attending anesthesiologist. At that point, it was not clear what was precipitating the hypertension or the wide complex tachycardia.

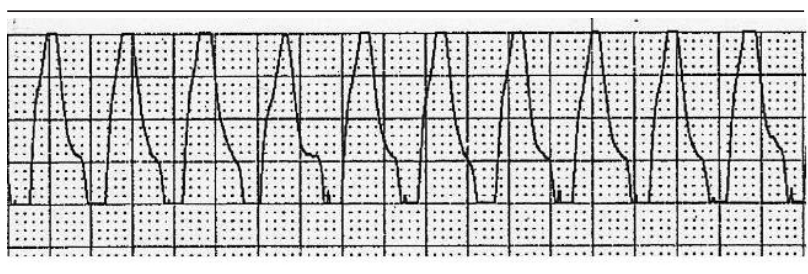

FIGURE 1 Telemetry strip showing a regular wide-complex tachycardia at 160 beats $\cdot \mathrm{min}^{-1}$.

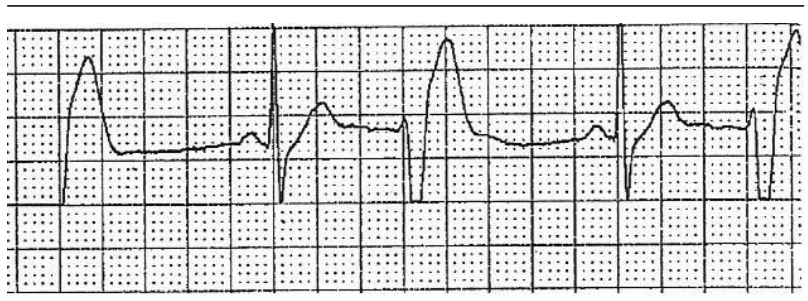

FIGURE 2 Telemetry strip showing ventricular bigeminy at 60 beats. $\min ^{-1}$.

Four minutes later, the BP had decreased to $120 / 70$ $\mathrm{mmHg}$ with $\mathrm{HR}=120$ beats $\cdot \mathrm{min}^{-1}$ ( sinus tachycardia). The patient became agitated, as his sedation wore off, and he resumed spontaneous respiration with $\mathrm{SpO}_{2}>$ 99\% on 35\% forced inspiratory oxygen. There was no indication of airway obstruction, and the patient was not biting down on the endotracheal tube prior to extubation. Given the patient was hemodynamically stable, requiring minimal respiratory support, and was neurologically appropriate, his trachea was extubated.

Immediately following extubation, the patient developed severe respiratory distress with a respiratory rate of 32 breaths. $\mathrm{min}^{-1}$ and $\mathrm{O}_{2}$ saturations of $68 \%$ with pink frothy secretions per os. Diffuse crackles were noted on chest auscultation. The patient's trachea was reintubated, and furosemide $40 \mathrm{mg}$ iv was given. The patient's heart rate subsequently decreased to 60 beats. $\mathrm{min}^{-1}$ in a bigeminal rhythm, then to 36 beats. $\mathrm{min}^{-1}$ with a wide complex ventricular escape (Figure 2). His pulse was then lost, consistent with a bradycardic, pulseless, electrical activity (PEA) arrest. Chest compressions were initiated; 1 amp each of epinephrine $(1000 \mu)$ and atropine $0.6 \mathrm{mg}$ were administered intravenously, and administered again at three minutes. The patient's heart rate subsequently increased to 171 beats. $\mathrm{min}^{-1}$ (regular and narrow complex). An electrocardiogram demonstrated anterior ST-segment elevation. The patient experienced a repeat PEA arrest $20 \mathrm{~min}$ later, with return to sinus tachycardia at 110 beats. $\mathrm{min}^{-1}$. A pulse was regained following $1 \mathrm{amp}$ of sodium bicarbonate $(50 \mathrm{mEq})$, in 
addition to repeated use of epinephrine and atropine. Norepinephrine, dopamine, and epinephrine infusions were required to maintain a mean arterial pressure of $>$ $65 \mathrm{mmHg}$, and repeated doses of lasix were given for worsening pulmonary edema.

While in the PACU, cardiology was consulted, and an urgent echocardiogram was performed revealing a globally hypokinetic left ventricle, without cavitary dilatation, and an ejection fraction of $<20 \%$. There was no evidence of significant valvular pathology. Given the ST-segment change on the electrocardiogram, the pulmonary edema, the hypotension, and the left ventricular (LV) dysfunction, the working diagnosis was cardiogenic shock. Subsequently, the ENT surgeon and the cardiologist updated the family regarding the preceding events and explained the need for the patient's immediate transfer to a tertiary care facility for coronary angiograophy and further stabilization.

Within two hours and 45 min of the patient's initial arrest in the PACU, he was transferred to a nearby tertiary care facility where he had a coronary angiogram. A $40 \mathrm{~mL}$ intra-aortic balloon pump (IABP) was inserted, under fluoroscopic guidance, via his right femoral artery. The IABP was set at $1: 1$, but did not significantly augment his systolic pressure, likely due to the elastic properties of young patients' descending aorta. His coronary angiogram revealed normal coronary arteries. The LV angiogram demonstrated severe LV dysfunction with an ejection fraction $<20 \%$ (available as Additional Material online at: www.cjajca.org). Hemodynamic parameters were consistent with cardiogenic shock $(\mathrm{LV}$ end-diastolic pressure $=$ $30 \mathrm{mmHg}$ ).

Despite a lasix infusion and three inotropic medications, the patient experienced worsening pulmonary edema, $\mathrm{O}_{2}$ saturations at approximately $80 \%$, and profound, hemodynamic compromise. He was transferred to the regional cardiac transplantation centre for consideration of percutaneous, cardiopulmonary support (CPS), as a bridge to possible cardiac transplantation. Cardiopulmonary support was initiated $14 \mathrm{hr}$ after the patient's surgery. The patient was successfully weaned off CPS after five days, and his ventilator was discontinued after five weeks. Although, at $48 \mathrm{hr}$ following the operation, a left ventricular ejection fraction (LVEF) of $<20 \%$ was again noted on echocardiography, the LVEF returned to normal (LVEF > 55\%) when repeated at six weeks. The patient continues to improve with respect to his neurologic impairment secondary to anoxic brain injury. Within 16 weeks of the initial surgery, his neurologic and cardiopulmonary status had almost fully recovered.

\section{Discussion}

Severe cardiovascular complications and death, postelective ENT surgery, are extremely rare and unexpected. We report a near fatal episode of cardiogenic shock, following elective septoplasty in an otherwise healthy 29 -yr-old male. Given the sequence of events presented herein, we propose the likely precipitating event to be a hypertensive crisis, secondary to systemically absorbed epinephrine-soaked cotton balls, followed by treatment with a beta-blocker.

Kalyanaraman et al. ${ }^{1}$ report a series concerning 12 patients treated with topical phenylephrine and/or submucosally injected epinephrine, perioperative ENT surgery, in previously healthy patients ranging in age from six to $41 \mathrm{yr}$. The predominant sequence of events reported in that series was consistent with the patient we present, including perioperative hypertension and treatment with a beta-blocker or calcium channel blocker resulting in pulmonary edema. The majority of patients had documented LV dysfunction, and $3 / 12$ suffered a cardiac arrest. Groudine et al. ${ }^{2}$ reported another series concerning nine patients with similar presentations; however, all of these patients received topical phenylephrine in conjunction with a beta-blocker.

The proposed pathophysiology is that of increased, alpha-receptor stimulation from a systemically absorbed, topical vasoconstrictor, resulting in increased systemic vascular resistance. Compensatory mechanisms, crucial in preventing flooding of the pulmonary vasculature, include increased heart rate and myocardial contractility. However, administering a beta-blocker (and possibly a calcium channel blocker) blunts this needed response. ${ }^{1,2}$ The cycle is precipitated by ongoing, unopposed, alpha stimulation when cardio-selective beta-blockers are administered.

Given these findings, the Phenylephrine Advisory Committee has outlined guidelines addressing intraoperative phenylephrine use. The guidelines include: careful dosing; monitoring of resulting hypertension, without immediate intervention; and avoidance of beta-blocker and calcium channel-blocker use for the treatment of perioperative hypertension. ${ }^{2}$ We suggest these guidelines should also address the use of intraoperative topical epinephrine.

While the combination of vasoconstrictors and beta-blockers as the precipitating event is most plausible, we need to explore alternate etiologies of cardiogenic shock for the patient we present. First, the most common cause of cardiogenic shock is secondary to acute ischemia. ${ }^{3}$ This etiology, including that of diffuse vasospasm, is less likely, as the patient had no 
significant, electrocardiographic changes; no cardiac risk factors were noted, and the coronary angiogram appeared normal. The second possibility is an Addisonian crisis, with overt cardiogenic shock and LV dysfunction. ${ }^{4}$ However, our patient had no persisting, electrolyte abnormalities, and he recovered completely without the need for stress-dose steroids. A third possibility is increased, endogenous secretions of catecholamines from an epinephrine-secreting pheochromocytoma. Cardiogenic shock has been described as the initial manifestation of this endocrine tumour and was diagnosed only after the patients recovered. ${ }^{5,6}$ However, the patient we present had normal urinary catecholamines following discontinuation of all inotropes. Ultimately, the cause of cardiogenic shock could be explained by a coincidental manifestation of fulminant, viral myocarditis. ${ }^{7}$ However, the patient had no viral prodrome and other described precipitating factors, consistent with that reported in the literature, making this diagnosis less likely. ${ }^{1,2}$ The fourth possibility is that the patient may have had an undisclosed history of cocaine use. Singh et al. ${ }^{8}$ reported a case of a 28 -yr-old male, with a history of cocaine use, who underwent opthalmological surgery. He suffered acute pulmonary edema, after intraoperative hypertension secondary to topical phenylephrine, and was treated with intravenous labetalol. This scenario, too, is unlikely, as further corroborating history gave no indication of previous substance use.

In conclusion, there are important clinical implications related to this case of a patient who experienced cardiogenic shock following nasal septoplasty, secondary to the combination of topical adrenaline and intravenous metoprolol.. A profound hypertensive response may ensue following systemic absorption of topical vasoconstrictors (including both phenylephrine and epinephrine). The complex cardiovascular interactions of treatment with beta-blockers and, possibly, calcium channel blockers, must be appreciated in order to prevent severe complications such as; pulmonary edema, cardiogenic shock, cardiac arrest, and potentially, death.

\section{References}

1 Kalyanaraman M, Carpenter RL, McGlew MJ, Guertin $S R$. Cardiopulmonary compromise after use of topical and submucosal alpha-agonists: possible added complication by the use of beta-blocker therapy. Otolaryngol Head Neck Surg 1997; 117: 56-61.

2 Groudine SB, Holliger I, Jones J, DeBouno BA. New York State guidelines on the topical use of phenylephrine in the operating room. Anesthesiology 2000; 92 : 859-64.
3 Massie BM, Shah NB. Evolving trends in epidemiologic factors of heart failure: rationale for preventive strategies and comprehensive disease management. Am Heart J 1997; 133: 703-12.

4 Wolff B, Machill K, Schulzki I, Schumacher D, Werner $D$. Acute reversible cardiomyopathy with cardiogenic shock in a patient with Addisonian crisis: a case report. Int J Cardial 2007; 116: e71-3.

5 Olsen SW, Deal LE, Piesman M. Epinephrine-secreting pheochromocytoma presenting with cardiogenic shock and profound hypocalcemia. Ann Intern Med 2004; 140: 849-51.

6 Kaye J, Edlin S, Thompson I, Leedma PJ. Pheochromocytoma presenting as life-threatening pulmonary edema. Endocrine 2001; 15: 203-4.

7 McCarthy RE 3rd, Boehmer JP, Hruban RH, et al. Long-term outcome of fulminant myocarditis as compared with acute (nonfulminant) myocarditis. N Engl J Med 2000; 342: 690-5.

8 Singh PP, Dimich I, Shamsi A. Intraoperative pulmonary oedema in a young cocaine smoker. Can J Anaesth 1994; 41: 961-4. 